\title{
The Reggio Approach in Motion: Documenting Experiences, Reflecting on Practice, and Disseminating the Ideas
}

\author{
Paolo Sorzio and Verity Campbell-Barr
}

\begin{abstract}
Paolo Sorzio is an associate professor at the University of Trieste, Italy, where he teaches qualitative research methodologies in educational research and design and documentation in educational services. His areas of research are professionalism in early childhood education and the impact of different learning environments on children's learning. He works closely with teachers and practitioners. His publications include "Day to Day in Italian Preschools: Environments for Learning and Development" in J. Georgeson and J. Payler (Eds.) International Perspectives on Early Childhood Education and Care (Open University Press, 2013). Email: psorzio@units.it

Dr. Verity Campbell-Barr is an associate professor in early childhood studies at Plymouth Institute of Education, Plymouth University, United Kingdom. She has more than 10 years of experience as a researcher in early childhood education and care (ECEC) and specializes in exploring concepts of quality and who and what informs them. Verity's latest research is focused on the role of the workforce in delivering quality ECEC services and how professionals come to know how to develop quality pedagogical environments. She coauthored Quality and Leadership in the Early Years (SAGE publications) and has just published Professional Knowledge and Skills in the Early Years (also with SAGE). Email: Verity.campbell-barr@plymouth.ac.uk
\end{abstract}

This article offers a cultural analysis of the materialization into cultural texts of a variety of educational experiences, political visions, and pedagogical approaches in order to understand the symbolic construction of the Reggio Emilia approach, highlighting its singularity and the motives of its dissemination. The analysis considers selected texts thatrefer to specificmethods of documenting children's activities to highlight the symbolic strategies that select, organize, and materialize a constellation of local experiences into a unified educational perspective. Through the innovative analysis of text composition, new dimensions of professionalism have emerged, challenging conventional approaches and promoting a valid alternative to the standardization of early childhood education. The dissemination of the Reggio approach through texts opens up new opportunities for early years practitioners to critically consider participation with families and calls on policymakers to reform the sector. The potential is created for cultural dialogue between families and professionals with different models of children's growth, thereby enriching the "funds of knowledge" at communities' disposal to promote children's approaches to language and symbolism.

Key words: Reggio approach; cultural objects; narratives of learning; participation structures; cultural dissonance
The Reggio Emilia approach has received widespread interest as an innovative early childhood education and care (ECEC) practice since the late 1980s. The approach has gained much currency because it makes explicit an articulated framework of child development, gives relevance to the manifold languages through which children's thinking can be manifested, and proposes open-ended educational activities as opportunities for learning. This approach is a valid alternative to the standardization process in ECEC, which relies on predefined learning outcomes and centers logical and linguistic competencies (Fuller, 2007). However, while the Reggio approach has much to offer, there is a need to present a critical articulation of the approach at a time when its ideas are often presented as prescriptions, frequently in component parts.

In this article, the concept of "cultural object" (Daston, 2008; Urban, 2001), as a collection of reflexive texts that imparts a force to a cultural practice, is applied to analyze the cultural objects produced within the Reggio Emilia approach in order to understand the symbolic construction of its singularity and the motives of its dissemination. For this purpose, some minor texts are selected, since they are more focused on the innovative methods of ministories and of the projects, rather 
than Reggio Children's major books, in which the experiences are only illustrative of the theoretical framework.

This article is based on the tenet that the texts produced within the Reggio approach become cultural objects through a deliberate process of selection, organization, and sedimentation of a constellation of experiences into a unified narrative in books, DVDs and exhibitions. The texts have supported the distribution of the Reggio approach internationally, leading to questions of whether the cultural conditions that gave rise to the approach have been evaded. Some risks of reinforcing differences in cultural capital in the dissemination of the Reggio approach are also addressed.

In this analysis, the focus is not on the children's performances but on their educational significance, as they are represented in the cultural objects that communicate "the Reggio approach."

\section{Theoretical framework: The construction of cultural objects}

When the participants in a cultural practice are engaged in a process of reflection, selection, and abstraction of their relevant experiences, they activate a process of "metaculture" that produces cultural objects. Therefore, "metaculture" is the process of framing a system of cultural practices as cultural expressions that define its origins and its core motives, its specific vocabulary, and the prototypical examples (Urban, 2001).

According to Lorraine Daston, the cultural objects that "become a magnet for intense interest" (Daston, 2008, p. 24) are characterized by the crystallization of a constellation of heterogeneous elements in a structure. It is not a contingent bricolage of experiences but a unified whole with a story to narrate, something that requires a careful design.

The cultural construction of the uniqueness of the Reggio approach is an articulated, historically developed production of texts as objects that talk (Daston, 2008). It is a semiotic construction that conveys the idea of the child-centered approach as self-evident. The adults are presented as closely listening to children's utterances and observing their intentional actions as windows into their natural, creative thinking; the Reggio-specific mode of documentation is intended to "make learning visible," as it would be without mediation (Project Zero \& Reggio Children, 2001). By crystallizing the reflection on its own practice into cultural objects, the Reggio Emilia educational experience acquires explicitness and consistency and becomes "the Reggio approach." The production of the material representations (books, DVDs, exhibitions), in turn, promotes the dissemination of the Reggio experiences and approach. Analysis of the texts produced within the Reggio experience is relevant because it is not just a description of what happened, it is an active process of selection of the experiences, their organization into a consistent narrative through argumentative strategies, and their solidification into a recognizable style with aesthetic and ethical components.

Greg Urban (2018) identifies two potential directions of cultural mobility: one is vertical, that is, across generations through direct participation in the practice of teacher training; the other is lateral, consisting in the crossing of boundaries of language and educational systems. This second direction motion disseminates cultural objects produced within the Reggio Children Foundation. The cultural objects, mainly texts, are signs that make the Reggio approach visible, understandable, and comparable with other experiences.

The overall functions of the texts produced within the Reggio Children Foundation are made explicit in the preface of the book series Coriandoli, in which it is stated that: 
the philosophical approach in Reggio Emilia pedagogy supports communicating education in diverse ways with writing where words and images interweave to make the educational approach adopted visible and perceptible. This is a new, hybrid language based on competencies unknown in traditional training for teachers, cross-bordering into new forms of knowledge to declare and underline the importance of an aesthetic dimension in teaching and learning. (Reggio Children, 2008, page ii)

This methodological statement is signed by the collective name of "Reggio Children," indicating a shared orientation in the Institution of the Municipality Preschools and Infant-Toddler Centres in Reggio Emilia. By creating complex texts to document the educational activities, the Reggio experience is solidified into cultural objects that can travel worldwide and provoke excitement, intellectual curiosity, and stimulation for changing practice in many different contexts.

This article analyzes some texts produced in the Reggio approach as cultural objects in order to identify their layouts and the relationships between different symbols that characterize the innovative "hybrid language" and the development of "new forms of knowledge." We highlight the mechanisms that have promoted the construction of the Reggio approach and its diffusion in the lateral direction. The texts are illustrative examples rather than a systematic sample.

The analysis seeks to consider:

- How has the Reggio approach been organized into cultural objects?

- How is children's learning constructed as narrative?

- Which textual characteristics make the educational experience in Reggio Emilia relevant for a global audience?

- What are the risks and opportunities of disseminating the Reggio approach through cultural objects?

\section{The textualization of the Reggio approach}

A system of cultural objects offers a frame of reference that makes the educational practice in the Reggio Emilia schools internally consistent and theoretically justified and promotes its dissemination. The theoretical foundations are presented in Making Learning Visible (Project Zero \& Reggio Children, 2001); the approach is grounded in Malaguzzi's deep sensitivity to children's potentialities to express themselves and learn by using different symbolic codes and is connected to an eclectic combination of Piagetian psychology, Bruner's socio-constructivism, and Gardner's theory of multiple intelligences. The origins are in the specific community of Reggio Emilia, which has been characterized by a high social capital since the Medieval era and then throughout the socialist movements in the $19^{\text {th }}$ century, to the antifascist ethos during WWII, as aptly expressed in the DVD Not Just Any Place (Fasano, 2008).

In subsequent sections, the analysis presented of the cultural objects associated with the Reggio approach (specifically the ministories and the projects) will provide details of the approach and its underlying philosophy. The analysis will contemplate the particular ways that both children and adults are constructed within the texts before considering the consequences of the anticipated embodiments of these constructions, particularly for professional practice. 


\section{The narrative composition of the ministories}

The ministories are short narratives about the children's thinking during meaningful experiences with objects. A learning event is narrated by presenting a few photographs that offer communicative clues of the children's joint actions, as well as by selecting some relevant utterances that the children express while they perform the actions, as gathered through video or audio recordings and fieldnotes.

The ministories are not intended to focus on the children's products or their actions in narrow tasks, with an expected outcome, but to appreciate the relevance of children's thinking in the process of manipulating simple materials to create their own artefacts, as a creative outcome. Indeed, each ministory revolves around an emergent thought the children work out to solve a cognitive deadlock in which they are entrapped while working out a project.

In gathering materials for the ministories, the school team (composed of atelieristas, pedagogistas, and teachers) keeps attention on the children's sentences that express their thinking processes in working out an intentional activity. Children's unfolding dialogues are complemented by pictures to highlight mutual attention, physical proximity, and coordinated movements on the objects.

One founding text of the Reggio approach as cultural object is The Hundred Languages in Ministories (Teachers and Children from Reggio Emilia, 2016). The text incorporates some documentation of the children's meaningful activities in Reggio schools from 1980 to 1994 . Some of the ministories had been previously presented in an exhibition in 1988.

In "Construction of Two Little Horses in Clay" we see photographs of one girl's hands manipulating clay to create her own small sculpture of a horse, and photographs of her intermediate productions. Photo 9 shows the child's hands trying to get the thin, fragile clay horse to stand up; her utterance gives a clear sense of what is going wrong: "He won't stand up. Come on, why don't you hold still?" (Teachers and Children from Reggio Emilia, 2016 , p. 4). Her visible manipulation of the horse transforms the clay into a new shape that offers new affordances for the child's thinking: She modifies her mental model of the clay horse and creates a completely new artefact representing the horse.

The ministory is structured to make evident the child's ingenious strategy to solve a deadlock situation; photographs alternate with utterances, and the lettering provides the rhythms of the child's thinking. One photo focuses on the partial artefact alone to emphasize the unworkable situation, which requires the child's new cognitive insight rather than a corrective manipulation. The child's utterance expresses wonder. The following frame shows her hands reworking the artefact, therefore suggesting her new insight.

In Mosaico di Grafiche, Parole, Materia (A Mosaic of Graphics, Words, and Raw Materials), a child who is 4 years, 10 months draws some flowers, smudging the colours; she comments that "it is like the wind effect on the flowers ... the wind melts them ... it is nice" (Reggio Children, 2015, p. 23). The teacher builds on the child's interpretation to ask the whole group if the wind can be drawn. The children offer their interpretation of the adult's proposal to extend their thinking by making new drawings and commenting on them. Another girl (5.2 years old) explains her drawing by stating that the wind goes everywhere; in her drawing the wind has made the flowers fly away, but "not all the flowers, some have remained otherwise one cannot understand that they are flowers" (Reggio Children, 2015, p. 30).

When recognizing some opportunities for further learning in the children's activities, the adult can intervene in the ongoing conversation, proposing relevant opportunities to the group in order to support the children's 
evolving understanding of the situation (in the Reggio vocabulary these crucial adult interactional moves are called rilanci). The rilanci can be translated as "extending questions"- they are oriented to promote further conversation by encouraging children to reflect on their own reasoning strategies in open-ended tasks.

The selection of children's utterances is intended to give a glimpse into their constant attribution of meaning to their actions. This is particularly relevant when their activity goes into an impasse. The recombination of the situational elements into a new cognitive perspective, as expressed in the presented utterances, offers evidence of the children's constructive processes as an integration of intentional thinking and sophisticated actions.

Structuring more encompassing narratives: The projects

An innovative cultural object is the series called Coriandoli, that is, small format books which introduce the educational activities with a more encompassing scope than the ministories. The series documents the unfolding of educational projects. In the Reggio approach, the projects are multistage activities, planned by the teachers, who think about the educational opportunities the children can experience by engaging in the activities. The projects are open ended, since the careful documentation of unfolding activities suggests to the adults to introduce changes according to the children's interests, proposals, and conjectures.

We Write Shapes That Look Like a Book (Pablo Picasso Infant Toddler Centre, 2008) is a small book that documents an articulated project, conducted by adults and 2- to 3-year-old children, oriented at making more visible the connections between the Infant-Toddler Centre and the town community. The very name of the project represents a creative use of wording that conveys multiple meanings: la città inattesa (city-in-waiting) can be interpreted in Italian both as "the unexpected city" and "the waiting city."

In this project, the children were invited to explore a large city park, to observe nature, to create hypotheses about the life of small animals in the park, and to gather natural materials to make artistic representations of their outdoor experience. An important part of the project was the children's return to the park to construct something original that could be appreciated by the people of the town.

The pictures highlight the children pointing to elements in the park's small ecological niches (emphasizing curiosity), exploring in groups (emphasizing friendship), manipulating natural objects like pebbles, sticks, and leaves (emphasizing intentionality and fine gestures). The park revealed both its rich hidden life, when carefully experienced (the unexpected city), and the potentialities for its development, as represented by the children's design of new paths to connect separated environments (the waiting city).

After analyzing the documentation of the outdoor activities, the teachers recognized a small composition of pebbles and sticks that the children had created in the park as the most suitable for engaging them in further symbolic reconstruction of their experience. The raw materials were brought to the centre and rearranged to design a new road in the park. In the next stage of the project, the children came back to the park and explored the disposition of its elements in a new perspective. They measured, explored again, and produced a symbolic representation on paper, including drawing the new road, and eventually they constructed an architectural model that was fixed on the ground of the park and visited by the Reggio citizens.

The book presents four sources of information: photographs of children's activities, children's drawings, children's utterances, and adults' comments. Two children making their own drawing are individually pictured and their product accompanies the photographs to give a sense of their intentional actions. The photographs of their drawing activity are framed to highlight commitment (each child is looking intensely at the drawing), and the hands of both are represented (one using the marker, the other holding the paper) to give a sense of the very young children's 
bodily coordination in their endeavour. To complete the narrative of the activity, there are pictures of the children observing their drawings projected onto a wall.

Strong consistency of complex educational activities is given by the children's use of symbolism to fix their experience into a new level of awareness: in the case of the city in-waiting, the children explore the park, make a material representation of their experience through drawings and manipulation of natural objects; they imagine new possibilities and create a collective artefact that becomes public. This double process is crucial to learning because symbolism articulates and gives meaning to the experiences, as well as opening up new experiential opportunities.

The narratives are focused on children's utterances and actions, but they appear as an adult construction: The adults frame the children's actions, select their utterances, and graphically compose the narrative sequence to give meaning to the situation and to open windows into the children's thinking processes. The adults' comments make use of mental verbs to interpret children's intentional activities (i.e., the adults' comments give more relevance to the children's intentions than to the outcomes of their activity); "the children's aesthetic research also becomes important, guiding them in their choice" (Pablo Picasso Infant Toddler Centre, 2008, p. 19). In the same book, "the tree rapidly becomes a mental image" (p. 24) and the children "are inclined and open to encounters with the new" (p. 42).

\section{The analysis}

The books are carefully designed to convey the educational principles of constructivism, as expressed by Carla Rinaldi (2006):

- Learning consists in the children's active transformation of their own mental schemes through engagement in meaningful experiences and constant reflection on the discrepancies between their intentionality and the real situation.

- Thinking and children's competencies can be expressed in different symbolic codes, such as figurative expression, dramatization, logic, and verbal language. Each emphasizes the natural competences of the children and they are not hierarchically organized.

- Children's thinking develops along unpredictable lines, rather than accommodating to an adult model of acceptable performance.

The cultural objects that document the educational activities and give consistency to the Reggio approach incorporate three layers of interpretation: the children's documenting of their experiences through utterances, drawings, and material models of reality; the adults' documenting the processes of children's learning in situation; and finally the narrative texts that organize educational experiences into a complex narrative, which gives the readers the meaning of education as a polyphonic activity, unfolding along carefully projected paths, but also open to unpredictability, to new possibilities arising from the children's explorations.

The cultural objects also present an idea of the child as constantly engaged in experience, thinking and talking about it, and using different symbols to represent and give meaning to it, individually or in a group.

Adults use sophisticated narrative techniques to make the subtle process of learning visible; therefore, they emphasize the idea of the competent child, rich with psychological potentialities that can be stimulated by the appropriate educational activities. 
The material representations of the Reggio approach are innovative along many dimensions. Books are rich in iconic support: photographs capture events of children manipulating materials, exploring the surroundings, creating a joint focus of attention. By taking pictures of the activity, the adults frame the processes rather than the children's products. When a picture frames a partial artefact, stilled from the flux of the activity, the sense of an impasse is conveyed. The reader shifts from an objective layer of interpretation, in which the children's gestures are seen, to a more subjective perspective, in which the artefact is the focus of careful intellectual inspection in order to reconsider its structure and devise new functional relationships among its features.

Framing, that is, "the pictorial boundary, the function of which [is] to close off the depicted scene against surrounding reality" (Prendeville, 2000, p. 159), is a relevant visual technique to give the reader the narrative rhythm of children's thinking. The frames can focus on children's visual orientation paying attention to the activity, the children's spatial vicinity, and their facial expressions of positive feelings. The reproduction of children's drawing highlights complex composition. The books' original layouts allow new relationships between pictures and words, giving the reader a sense of the children's thinking processes while engaged in intentional actions. The figurative descriptions of the children's activities are supported by the selection of their utterances to offer a window into the children's meaning making in situation.

The Reggio approach overtakes the conventional educational iconography, which implies adherence to a single point of view, a figure/background composition, a limited palette of colours. The books, as cultural objects, make manifest different educational presuppositions, which are closer to the artistic avant-gardes of the twentieth century - the children are encouraged to explore different representational modes, to express their thinking; composition and design are more appreciated than conformity to an expected format. As modernism in art tends to make the compositional process visible, the texts in the Reggio approach are intended to "make learning visible."

The ministories as well as the Coriandoli project make salient some relevant aspects of children's thinking. However, both groups of narratives are constructed by the selection of a few images and utterances in order to give a sense of children's learning. We are given only some interactional moments, when the children's words are accompanied by an invitation from the teacher to extend their thinking. However, the fine-grained interactional situation is not available, and therefore it is difficult to appreciate the whole structure of children's participation, that is, the set of educational presuppositions that orient the participants in the appropriate interpretation of the discursive acts in a communicative situation, the register of speaking and the culturally appropriate frames of reference (O'Connors \& Michaels, 1996). As a consequence, in the cultural objects developed in the Reggio approach, the children's thinking is separated from the background of cultural presuppositions about the children's status in schools, the implicit role of adults, the learning outcomes that are valued within the approach. We get some original metaphors, but we cannot recognize the communicative contexts that support their emergence.

The cultural objects offer a representation of the Reggio experience as a consistent approach that can make recognizable the relevant educational principles of introducing an innovative image of the child, as rich in competences and symbolism, with potentialities for further development. Learning is also conceptualized in a new perspective. The children are active constructors of their own development through educational encounters that are democratic in nature: respectful, cooperative, proactive.

Taken together, these characteristics of the Reggio approach, as they are made explicit in the cultural objects, represent a viable alternative to the standardization of ECEC, which is based on rigid interactional procedures, closed tasks, and expected models of acceptable performance.

As Rinaldi, in conversation with Peter Moss, has maintained, "In an age of educational conformity in Early 
Childhood Education, Reggio Emilia offers the hope that a different way of thinking and acting exists. It represents an island of dissent and creates an opportunity for change" (Rinaldi, 2004, p. 3 ).

The educational system developed in Reggio Emilia solidifies a variety of cultural dimensions (namely, the political struggle for civil rights, the pedagogical vision of children as agents of their own learning, and innovative symbolic representations) into a consistent system of texts that gives the Reggio approach its relevance. The texts make evident the well-interconnected elements of child-centered practice. The dissemination of the approach has the potential to introduce positive changes in the early childhood education culture worldwide, since it promotes the quality of the environment to support children's initiative, responsive adult-child relationships, and dialogue with peers. As a consequence, educators are invited to orient themselves differently, adopting different values to those implied by standardized approaches. Inspired by the Reggio experience, practitioners design complex activities, give children voice, and jointly reflect on experiences in order to foster children's potentialities and interests. This in turn promotes a professional culture of educational practice, based on innovative texts of documentation. As many researchers have highlighted (McCoy et al., 2017; Sylva et al., 2007), quality in early childhood services is a relevant predictor of school success, personal well-being, and community participation. Therefore, the dissemination of the Reggio approach calls on policymakers to give value to and sustain professionalism in the early years sector through staff qualification, in-service training, and good salaries.

\section{Risks and opportunities}

Originally, the Reggio approach was supported by the municipality, since it was considered consistent with the political perspective of promoting the community's social capital. However, it is worth emphasizing for those who have not visited Reggio Emilia that not all ECEC centres follow the approach within the municipality. Further, despite the provision of ECEC services across Italy being characterized by a north-south divide in regard to levels of provision (Fortunati, 2015), many municipalities offer good-quality ECEC services but do not adopt the Reggio approach and have not received international recognition (Tobin, 2005). The approach, therefore, cannot be regarded as representative of Italy.

It is the global transference of Reggio's cultural artefacts that has resulted in the Reggio approach becoming a (selected) global quality standard. The development of global objects that travel internationally is well illustrated upon visiting the Loris Malaguzzi International Centre, where visitors can access various texts that have been translated into a number of different languages. The global dissemination is mostly supported by the predominance of the use of the English language, but with no consideration of how the Anglo-American paradigm can ascribe a different cultural meaning onto native-language intentions in the process of translation (see Jensen, 2016).

The representation of the different educational presuppositions that are manifested within the Reggio approach supports the international dissemination of the texts, because with no single educational representation or goal to be reached, international audiences are potentially provided with an opportunity to interpret the texts in ways that are culturally (and educationally) meaningful. However, becoming incorporated into objects that travel in a globalized society, the Reggio approach undergoes the risk of receiving a different set of meanings when recontextualized into different socio-political conditions, because it requires a relevant financial, architectural, and pedagogical investment. For example, the involvement of parents within the Reggio centres is key, and is in keeping with global quality standards for parental participation (e.g., Organisation for Economic Co-operation and Development, 2015), but the socialist political origins of parents' involvement are lost in the globalization of the approach (Tobin, 2005). Educators risk a performative parental engagement that is closer to the prescriptive quality standards of organizations such as the OECD (Campbell-Barr \& Leeson, 2016) as opposed to one that is based on a 
deep connection between the ECEC centre and the wider community (Tobin, 2005). "Real participation" (Rinaldi, 2006) requires co-responsibility and developing new ways of communicating with families, where educators meet and engage with the community in multiple ways.

The Reggio approach prescribes a particular way of thinking and acting onto those who are working with the children. The approach is reminiscent of the feminist ethic of care (see, e.g., Noddings, 2010, 2012) and the careful way in which the adult appreciates the needs of the other (the child), thus upholding respectful listening. Further, the emphasis on children's autonomy promotes democratic principles that are largely consistent with the middle-class ideals of many international educators, extending the approach's global transference (see Tobin, 2005). However, despite its democratic appeal, it is still the adults who give voice to the child(ren) and attentively engross in documenting the child(ren)'s actions in ways that pace and sequence the child(ren)'s actions. As it appears in our analysis of its texts, the approach seems to give little consideration to how support for children's autonomy is managed in group-based ECEC environments. Not only are there diverse children with different cultural backgrounds, but workforces can be equally varied.

\section{Hybridizing the Reggio approach}

The uncritical circulation of the Reggio approach and its piecemeal application, separated from its inclusive ethos, may reproduce unequal access to the opportunities of early schooling. In the case of emphasizing only the dimension of the child's autonomy and self-regulative learning, there is a risk of overlooking alternative, although rich and consistent, patterns of child rearing, especially in minority and working-class communities. Minority and working-class families cannot be homogenized as groups; evidence suggests that ECE professionals will encounter many different parental expectations regarding child rearing and child participation.

As one example, according to Bruce Fuller's (2007) encompassing review of anthropological research on child rearing, immigrant Latino families develop different participation structures for children in their householdschildren may deal with different tasks and communicate through different patterns of interaction than those privileged in the Reggio approach. Latino families may expect the teachers to lead the activities in preschools and make visible the appropriate modes of using literacy skills (Goldenberg \& Gallimore, 1995). In these contexts, the child may be required to be an active observer of an expert model in action when engaged in a structured activity (Rogoff, 2003).

In her fieldwork in different communities in southeastern United States, Shirley Brice Heath (1982) observed specific patterns of use of children's books in different households, each offering different types of linguistic tasks to children and therefore emphasizing different aspects of story-telling competencies. As the author highlighted, in narrating stories to their children, members of African-descent unschooled families tended to give value to the contextualization of a narrative into their everyday life experiences, rather than considering a narrative text as a self-contained system of meanings, as occurs in middle-class families in the same geographical area. The Africandescent families emphasized rhythmical patterns and personal judgements more frequently than the true meaning of the stories. They made a larger use of linguistic markers that make references to the external world of the text and a lesser use of reference among elements expressed in the text. These patterns of interaction mediated by books show different perspectives of pre-literacy competence from those expected in the early years of schooling; nonetheless they are equally complex and flexible from a linguistic point of view.

The dissemination of the Reggio approach is an opportunity for early years services to meet a fully fledged culture of childhood and an innovative perspective on professionalism in working with children. The dissemination process can also be an opportunity for the Reggio perspective to grow in cultural expression when meeting adult-child 
interactional patterns that are different from those developed in Italian mainstream communities. This process may create a hybrid zone of cultural dialogue. Modalities of children's narrative as developed in Reggio experiences may be complemented by the "oral poetry" emphasis on rhythmic, expressive, and improvisational patterns of communication that children can learn in their early experiences with books, as Heath (1982) recognized.

In this perspective, documentation may become an interesting shared cultural object for dialogue and exchange of experiences between families and professionals that allows a bidirectional movement of metacultural objects: from the Reggio approach to communities and from communities to Reggio-inspired schools, as "funds of knowledge" (Moll, Amanti, Neff, \& Gonzales, 1992).

\section{Conclusion}

The Reggio approach, as it is symbolically constructed in its cultural objects, has disseminated a whole system of a culture of childhood. Textualization represents the motion force of the Reggio experience, since it solidifies into a consistent cultural object a long history of political struggle for civil rights, an educational ethos of inclusion and respect for all the children, and innovative documentation of children's experiences, dialogue, and thinking processes.

Reminiscent of modernism in figurative art, the artistic composition of ministories highlights children's constant attribution of meaning to their actions and the role of dialogue in enhancing their thinking processes. The Coriandoli book series creates an articulated narrative of multistage activities that are worked out to engage children in exploring and understanding relevant sites in their community. In the unfolding of the activities, the children develop verbal, numerical, geometrical, and figurative languages to express and share ideas. The approach therefore requires the children to work in particular ways, but it also requires professionals to consider their engagement with children and their families. Presenting children's learning as part of their participation in the life of their community, the Reggio approach does not limit its contribution to the presentation of innovative activities. It offers an alternative framework to the conventional (standardized) approaches to ECEC.

Through the dissemination of these innovative documentation texts, the Reggio approach has become a valid alternative to the traditional approach of ECEC, which is based on limited children's initiative, on adult-led routines, and on purely anecdotal documentation related to children's products. The Reggio approach is also an alternative to the standardization of ECEC, based on assessment of children's levels of competence. From the point of view of professionalism in the early years field, the dissemination of the cultural objects produced within the Reggio approach enhances awareness of the relevance of well-designed environments and warm and stimulating patterns of child-adult communication for children's well-being and community welfare. It promotes the development of an innovative culture of education in the early years sector, as well as a reform of the services and of the profession. However, in its travels across countries and communities, the Reggio approach is expected to be hybridized with different communication patterns, artefacts, and figurative styles in order to share its inclusive ethos and to increase educational opportunities for all. 


\section{References}

Campbell-Barr, V., \& Leeson, C. (2016). Quality and leadership in the early years. London, UK: SAGE.

Daston, L. (2008). Introduction. In L. Daston (Ed.), Things that talk: Object lesson from art and science (pp. 1-24) Cambridge, MA: ZoneBooks.

Fasano, M. (2008). Not just any place [DVD]. Reggio Emilia, Italy: Reggio Children.

Fortunati, A. (Ed.). (2015). Rapporto di monitoraggio del piano nidi [progress report on ECEC]. Sponsored by the Italian Government Department of Policies for Families, The National Centre of Documentation on Childhood and Adolescence, and the Istituto degli Innocenti. Retrieved from https://www.minori.gov.it/it/minori/rapporto-di-monitoraggio-del-piano-nidi-al-31-dicembre-2015-0

Fuller, B. (2007). Standardized childhood: The political and cultural struggle over early education. Palo Alto, CA: Stanford University Press.

Goldenberg, C., \& Gallimore, R. (1995). Immigrant Latino parents' values and beliefs about their children's education: Continuities and discontinuities across cultures and generations. In P. Pintrich \& M. Maehr (Eds.), Advances in motivation and achievement (Volume 9; pp. 183-227). Greenwich, CT: JAI Press.

Heath, S. B. (1982). What no bedtime story means. Narrative skills at home and at school. Language and Society, 11(2), 49-76. https:// doi.org/10.1017/S0047404500009039

Jensen, J. J. (2016). The Danish pedagogue education. In M. Vandenbroeck, M. Urban, \& J. Peeters (Eds.), Pathways to professionalism in early childhood education and care (pp. 15-28). Oxon, UK: Routledge.

McCoy, D., Yoshikawa, H., Ziol-Guest, K., Duncan, G., Schindler, H., Magnuson, K., Yang, R., Koepp, A., \& Shonkoff, J. (2017). Impacts of early childhood education on medium- and long-term educational outcomes. Educational Researcher, 46(8), 474-487. https:// doi.org/10.3102\%2F0013189X17737739

Moll, L. C., Amanti, C., Neff, D., \& Gonzalez, N. (1992). Funds of knowledge for teaching: Using a qualitative approach to connect homes and classrooms. Theory into Practice, 31(2), 132-141. https://doi.org/10.1080/00405849209543534

Noddings, N. (2010). Moral education in an age of globalization. Educational Philosophy and Theory, 42(4), 390-396. https://doi. org/10.1111/j.1469-5812.2008.00487.x

Noddings, N. (2012). The caring relation in teaching. Oxford Review of Education, 38(6), 771-781. https://doi.org/10.1080/03054985.2 012.745047

O’Connor, M. C., \& Michaels, S. (1996). Shifting participant frameworks: Orchestrating thinking practices in group discussion. In D. Hicks (Ed.), Discourse, learning, and schooling (pp. 63-103). Cambridge, UK: Cambridge University Press.

Organisation for Economic Co-operation and Development. (2015). Starting Strong III: A quality toolbox for early childhood education and care. Paris: Author.

Pablo Picasso Infant Toddler Centre. (2008). We write shapes that look like a book. Reggio Emilia, Italy: Reggio Children.

Prendeville, B. (2000). Realism in 20 th-century painting. London, UK: Thames \& Hudson.

Project Zero \& Reggio Children (2001). Making learning visible: Children as individual and group learners. Reggio Emilia, Italy: Reggio Children.

Reggio Children. (2008). Introduction. In Pablo Picasso Infant Toddler Center (Author), We write shapes that look like a book (pp. i-ii). Reggio Emilia, Italy: Author.

Reggio Children. (2015). Mosaico di grafiche, parole, materia (A mosaic of graphics, words, and raw materials). Reggio Emilia, Italy: Author

Rinaldi, C. (2004). Perché a Reggio? Un dialogo tra Peter Moss e Carlina Rinaldi (Why in Reggio? A dialogue between Peter Moss and Carlina Rinaldi). Bambini in Europa, 2-3. 
Rinaldi, C. (2006). In dialogue with Reggio Emilia: Listening, researching, and learning. London, UK: Routledge.

Rogoff, B. (2003). The cultural nature of human development. Oxford, UK: Oxford University Press.

Sylva, K., Taggart, B., Siraj-Blatchford, I., Totsika, V., Ereky-Stevens, K., Gilden, R., \& Bell, D. (2007). Curricular quality and day-to-day learning activities in preschool. International Journal of Early Years Education, 15(1), 49-65. https://doi. org/10.1080/09669760601106968

Teachers and Children from Reggio Emilia. (2016) The hundred languages in ministories: Told by teachers and children from Reggio Emilia. Worcester, MA: Davis. Original work published 1993.

Tobin, J. (2005). Quality in early childhood education: An anthropologist's perspective. Early Education and Development, 16(4), 421434. https://doi.org/10.1207/s15566935eed1604_3

Urban, G. (2001). Metaculture: How culture moves through the world. Minneapolis: University of Minnesota Press.

Urban, G. (2018). The role of metaforces in cultural motion. Signs and Society, 6(1), 256-280. https://doi.org/10.1086/694550 